\title{
Comunicación
}

\section{PERFIL BIOQUÍMICO SANGUÍNEO HEPÁTICO Y RENAL EN EL SAJINO (Tayassu tajacu) CRIADO EN CAUTIVERIO EN LA AMAZONÍA PERUANA}

\author{
Luigi Schettini Z. ${ }^{1}$, Olga Li E. ${ }^{2}$, Hugo Gálvez C. ${ }^{3}$, Enrique Montoya G. ${ }^{3}$ y \\ Nofre Sánchez P. ${ }^{3}$
}

\section{Abstract}

The objective of this study was to establish reference serum values for bilirrubin (total and direct), alanine amino transferase (ALT), aspartate amino transferase (AST), alkaline phosphatase, cholesterol, total protein, albumin, urea, and creatinine in healthy collared peccary (Tayassu tajacu) kept under captivity in the Amazonian jungle of Peru (Loreto, Iquitos). A total of 28 adult animals (14 males and 14 females) were used. Blood samples $(7 \mathrm{ml})$ were collected from the safen vein. Serum values were: Total bilirrubin: 0.7 $\pm 0.2 \mathrm{mg} / \mathrm{dl}$; direct bilirrubin: $0.2 \pm 0.1 \mathrm{mg} / \mathrm{dl}$; ALT: $26.5 \pm 9.1 \mathrm{UI} / \mathrm{l} ;$ AST: $15.9 \pm 8.4 \mathrm{UI} / \mathrm{l}$; alkaline phosphatase: $27.5 \pm 15.5 \mathrm{UI} / \mathrm{l}$; cholesterol: $94.4 \pm 20.2 \mathrm{mg} / \mathrm{dl}$; total protein: $8.5 \pm$ $1.1 \mathrm{~g} / \mathrm{dl}$; albumin: $4.4 \pm 0.5 \mathrm{~g} / \mathrm{dl}$; urea: $58.1 \pm 11.1 \mathrm{mg} / \mathrm{dl}$; and creatinine: $2.2 \pm 0.5 \mathrm{mg} / \mathrm{dl}$. It was concluded that serum values were similar to other results reported in the literature and without statistical differences due to sex.

Key words: collared Peccary, Tayassu tajacu, serum biochemistry, captivity

La diversidad biológica es uno de los recursos más importantes en la Amazonía peruana, porque sirve como fuente de alimentos a las poblaciones amazónicas y porque genera fuentes de trabajo en la agroindustria de la región; de allí que se hace imperativo encaminar esta biodiversidad hacia un aprovechamiento más sustentable, sin destruir o alterar los ecosistemas naturales (Brack Egg, 2000).

El sajino o pécari de collar (Tayassu tajacu) se caza y se cría en la Amazonía para la utilización de su carne y la exporta- ción de pieles. La importancia de este animal en el país radica en su alta participación, como caza de subsistencia, en la dieta de la población amazónica (Bodmer et al., 1990) y porque ubica al Perú como el único país exportador legal de pieles de sajino, convirtiendo su crianza en una actividad promisoria para la región.

El desconocimiento de orientaciones sanitarias en torno a su susceptibilidad a enfermedades parasitarias e infecciosas y de los niveles biológicamente aceptables de parámetros fisiológicos, así como de estrate-

\footnotetext{
${ }^{1}$ Práctica privada

${ }^{2}$ Laboratorio de Patología Clínica, FMV-UNMSM. E-mail: olgalie@ hotmail.com

${ }^{3}$ Estación Experimental del Centro de Investigaciones IVITA-Iquitos, FMV-UNMSM
} 
gias de manejo en cautividad dificultan la difusión de su crianza en cautiverio, en niveles que permitan reemplazar la oferta de pieles para exportación que provengan de la caza de subsistencia.

La estandarización de parámetros fisiológicos clínicos (sangre, heces, bioquímica sérica) contribuye a la identificación del estado clínico de una población o de un individuo, lo que facilita el diagnóstico temprano de procesos patológicos infecciosos, minimizando la morbilidad y la mortalidad. Por lo tanto, se realizó un estudio para determinar los valores normales de la bioquímica sanguínea hepática y renal en el sajino (Tayassu tajacu) criado en cautiverio en la Amazonía peruana. El estudio se realizó entre agosto y octubre del 2003 con animales del zoocriadero Biodiversidad Amazónica (BIOAM), ubicado en el km 23 de la carretera Iquitos-Nauta, en la ciudad de Iquitos, departamento de Loreto, Perú.

Las condiciones climáticas de Loreto, corresponden al bosque húmedo tropical amazónico, con un promedio de temperatura anual entre 22 y $32{ }^{\circ} \mathrm{C}$, con una variación diaria de $4{ }^{\circ} \mathrm{C}$ y un porcentaje de humedad media del $85 \%$. La precipitación anual oscila entre los 1,500 y los $3,000 \mathrm{~mm}$ con un promedio de 2,600 $\mathrm{mm}$.

Se colectó sangre de los 28 sajinos adultos (14 hembras y 14 machos) existentes en el zoocriadero para el análisis de los parámetros de bioquímica sanguínea. El peso promedio de los individuos fue de $23.1 \mathrm{~kg}$ ( 24.7 en machos y $21.4 \mathrm{~kg}$ en hembras). No se colectó a las crías o juveniles debido a que la edad es un factor que influye en los resultados de algunas pruebas de bioquímica sérica.

Los animales presentaban aretes de plástico como sistema de identificación. La dieta ofrecida era variada, dependiendo de la disponibilidad de productos de la zona (yuca, semillas y frutos), forraje y un suplemento a base de harina de soya y cascarilla de arroz, con una premezcla de vitaminas y minerales. El agua fue administrada ad libitum. Los animales se encontraban en condiciones sanitarias aparentemente normales, y estaban recibiendo un tratamiento antiparasitario con ivermectina o doramectina al 1\%, para eliminar los parásitos internos (Strongyloides sp., Ascaris sp., Strongylus sp. y Balantidium coli) encontrados mediante monitoreos parasitarios semanales.

La obtención de muestras de sangre se realizó entre las 08:30 y 10:30 horas. Los animales se inmovilizaron con redes colectándose $7 \mathrm{ml}$ de sangre de la vena safena en tubos sin anticoagulante. Las muestras fueron trasladadas al laboratorio en cajas térmicas con bolsas refrigerantes para la obtención del suero por centrifugación a 3,000rpm durante 10 minutos. Los viales conteniendo el suero fueron congelados a $-20{ }^{\circ} \mathrm{C}$ hasta su posterior procesamiento y evaluación en la Estación Experimental del Centro de Investigaciones IVITA-Iquitos y en el Laboratorio de Patología Clínica de la Facultad de Medicina Veterinaria, Universidad Nacional Mayor de San Marcos, Lima.

Se utilizaron métodos colorimétricos y cinéticos para el procesamiento de las muestras, y se observaron las condiciones de tiempo y temperatura adecuadas para la reacción. La lectura de la absorbancia se realizó en el espectrofotómetro Thermo Spectronic modelo Genesys 20 y en el espectrofotómetro UV (Photometer 4010 Manheim Boehringer), con una longitud de onda que varió entre 340 a $630 \mathrm{~nm}$.

Se determinaron los niveles séricos de bilirrubina, alanino amino transferasa (ALT), aspartato amino transferasa (AST), fosfatasa alcalina, colesterol, proteínas totales, albúmina, urea y creatinina, utilizando kit comerciales (Labtest y Wienner Lab).

Los valores obtenidos fueron evaluados mediante estadísticas descriptivas, empleando la media aritmética como medida de tendencia central y la desviación estándar como 
Cuadro 1. Valores de bioquímica sérica para evaluar función hepática en sajinos adultos de ambos sexos, criados en cautiverio en la Amazonía peruana (2003)

\begin{tabular}{lrrrr}
\hline & \multicolumn{2}{c}{$\mathrm{x} \pm$ d.e. } & \multicolumn{2}{c}{ Rango } \\
\hline Bilirrubina total (mg/dl) & 0.7 & \pm 0.2 & $0.2-1.3$ \\
Bilirrubina directa (mg/dl) & 0.2 & \pm 0.1 & $0.0-0.5$ \\
ALT (UI/l) & 26.5 & \pm 9.1 & $12-54$ \\
AST (UI/l) & 15.9 & \pm 8.4 & $5-34$ \\
Fosfatasa alcalina (UI/l) & 27.5 & \pm 15.5 & $7.8-62.1$ \\
Colesterol (mg/dl) & $94.4 \pm 20.2$ & $59.2-150.8$ \\
Proteína total (g/dl) & $8.5 \pm 1.1$ & $7.1-10.9$ \\
Albúmina (UI/l) & $4.4 \pm 0.5$ & $3.2-5.6$ \\
\hline
\end{tabular}

Cuadro 2. Valores de bioquímica sanguínea para evaluar la función renal en sajinos adultos de ambos sexos, criados en cautiverio en la Amazonía peruana (2003)

\begin{tabular}{lcc}
\hline & $\mathrm{x} \pm$ d.e. & Rango \\
\hline Urea $(\mathrm{mg} / \mathrm{dl})$ & $58.1 \pm 11.1$ & $39.0-81.0$ \\
Creatinina $(\mathrm{mg} / \mathrm{dl})$ & $2.2 \pm 0.5$ & $1.4-3.3$ \\
\hline
\end{tabular}

medida de variación. Asimismo, se utilizó la prueba estadística "t" Student para determinar diferencias significativas entre sexos.

La estadística descriptiva de los resultados obtenidos en el presente estudio se presenta en los cuadros 1 y 2 .

La determinación de bilirrubina es útil en el diagnóstico de las enfermedades hemolíticas y diferentes tipos de hepatopatías (Guyton, 1989). Los valores de bilirrubina total obtenidos en sajinos (Tayassu tajacu) adultos $(0.7 \pm 0.2 \mathrm{mg} / \mathrm{dl})$ fueron similares a los valores reportados para esta especie (0.05 $0.9 \mathrm{mg} / \mathrm{dl}$ ) por Wallach et al. (1971); sin em- bargo, los valores de bilirrubina total y conjugada o directa fueron superiores a los obtenidos por ISIS (1999). Posiblemente, estas diferencias puedan deberse a la localización geográfica, los hábitos alimenticios y al tipo de manejo en cautiverio (Meyer y Harvey, 1998).

Los valores de ALT obtenidos (26.5 \pm 9.1 UI/l) fueron similares a los reportados por otros autores (Lochmiller et al., 1985; ISIS, 1999) para esta especie. La ALT se localiza en el tejido hepático y un cambio de permeabilidad en las membranas celulares provoca la liberación de ALT a la circulación sanguínea (Kaneko y Cornelius, 1971). 
El aumento de la AST sérica sugiere necrosis hepática o muscular (Sodikoff, 1996). Los valores obtenidos de AST $(15.9 \pm 8.4$ UI/l) son menores a los reportados por otros autores (Lochmiller et al., 1985; ISIS, 1999) para esta especie, aunque similares a los valores reportados para el cerdo doméstico (Merck, 2000).

Los valores de fosfatasa alcalina (27.5 $\pm 15.5 \mathrm{UI} / \mathrm{l})$ y de colesterol $(94.4 \pm 20.2 \mathrm{mg}$ / dl) fueron similares a los reportados por otros autores (Lochmiller et al., 1985; Wallach et al., 1971) para esta especie. La fosfatasa alcalina es útil como indicativo de obstrucción biliar, en tanto que se produce hipercolesterolemia en casos de colestasis intrahepática (Benjamín, 1991) y posthepática (Lochmiller et al., 1985; ISIS, 1999).

Similarmente, los valores obtenidos de proteínas totales $(8.5 \pm 1.1 \mathrm{~g} / \mathrm{dl})$, albúmina $(4.4 \pm 0.5 \mathrm{~g} / \mathrm{dl})$ y urea $(58.1 \pm 11.1 \mathrm{mg} / \mathrm{dl})$ fueron superiores a los reportados en la literatura para esta especie (Lochmiller et al., 1985; ISIS, 1999). Se presenta hipoalbuminemia cuando existe enfermedad hepática difusa crónica, especialmente cirrosis (Benjamín, 1991). Por otro lado, la urea aumenta en la sangre por insuficiencia renal crónica y aguda y por obstrucción de las vías urinarias o cuando disminuye el flujo de sangre a través del riñón (Kaneko y Cornelius, 1971). Se debe considerar que los valores de urea se ven influenciados por las proteínas de la dieta, el catabolismo proteico, la edad y el sexo (Benjamín, 1991).

Los valores obtenidos de creatinina $(2.2$ $\pm 0.5 \mathrm{mg} / \mathrm{dl}$ ) están dentro del rango reportado en la literatura para esta especie (ISIS, 1999). La excreción de creatinina es mucho más fácil que la urea por lo que el daño renal es mayor cuando aparecen valores anormales de creatinina en sangre (Doxey, 1987).

Se debe considerar que los valores encontrados en este estudio han sido comparados con resultados obtenidos en Estados Uni- dos de Norteamérica y en Europa. Estas regiones geográficas tienen condiciones climáticas muy diferentes a las registradas en la Amazonía peruana. Asimismo, en los trabajos realizados no se especifica la edad de los animales utilizados, el tipo de crianza (extensiva o intensiva) ni el tipo de alimentación recibida. Estos factores (clima, edad, manejo, nutrición, etc.) influyen en los resultados de las diferentes pruebas y pueden ser el motivo de la diferencia encontrada en algunos de los parámetros de bioquímica sanguínea encontrados en el presente estudio.

\section{Conclusiones}

En el presente estudio se pudo establecer un perfil bioquímico sanguíneo para evaluar la función hepáticay renal en el sajino (Tayassu tajacu), permitiendo conocer parámetros fisiológicos importantes para la salud animal en esta especie. Así mismo, no se encontraron diferencias estadísticas significativas en los valores de bioquímica sanguínea entre machos y hembras.

\section{Literatura Citada}

1. Benjamín, M. 1991. Manual de patología clínica en veterinaria. $3^{\mathrm{a}}$ ed. p 269300. Ed. Limusa. México.

2. Bodmer, R.; N. Bendayán; L. Moya; T. Fang. 1990. Manejo de ungulados en la Amazonía peruana: análisis de su caza y comercialización. Boletín de Lima 70: 49-56.

3. Brack Egg, A. 2000. Biodiversidad amazónica y manejo de fauna silvestre. En: Manejo de fauna silvestre de la Amazonía. University of Florida UNDP/ GEF, Instituto de Ecología. p 3-14. La Paz, Bolivia.

4. Doxey, D.L. 1987. Patología clínica y procedimientos de diagnóstico en veterinaria. $2^{a}$ ed. p 49-65. Ed. Manual Moderno. México. 
5. Guyton, A.C. 1989. Fisiología y fisiopatología básicos. $9^{a}$ ed. p 961-966. Ed. McGraw Hill. USA.

6. International Species Identification System (ISIS). 1999. Clinical pathology records report-ISIS/In house reference values mammals. Disponible en: htpp:/ www.worldzoo.org

7. Kaneko, J.; C.E. Cornelius. 1971. Clinical biochemistry of domestic animals. $2^{\text {dd }}$ ed. $p$ 161-221. Academic Press. New York, USA.

8. Lochmiller, R.L.; E.C. Hellgren; L.W. Varner; W.E. Grant. 1985. Serum and urine biochemical indicators of nutritional status in adult female collared peccaries,
Tayassu tajacu (Tayassuidae). J. Wildlife Manage. 45: 477-488.

9. Meyer, D.J.; J.W. Harvey. 1998. Veterinary laboratory medicine: interpretation \& diagnosis. ${ }^{\mathrm{a}}$ ed. p 14-17. W.B. Saunders. Philadelphia, USA.

10. Merck. 2000. El manual Merck de veterinaria. $5^{\mathrm{a}}$ ed. Ed. Océano. Barcelona, España. 2455 p.

11. Sodikoff, C.H. 1996. Pruebas diagnósticas y de laboratorio en las enfermedades de pequeños animales. $2^{\mathrm{a}}$ ed. p 4, 6 , 12, 16. Ed. Mosby. España.

12. Wallach, J.D.; W.C. Russell; K. Herman. 1971. The normal hematology and serum chemistry of the collared peccary. J. Zoo Anim. Med. 2: 31-36. 